\title{
Surtos de fotossensibilização primária em equídeos causados por Froelichia humboldtiana ${ }^{1}$
}

\author{
Sheila Nogueira Ribeiro Knupp ${ }^{2 *}$, Caio Cesar Borburema ${ }^{3}$, Temístocles Soares \\ de Oliveira Neto ${ }^{3}$, Rosane de Medeiros ${ }^{4}$, Leonardo Sidney Knupp ${ }^{5}$, Franklin \\ Riet-Correa ${ }^{4}$ e Ricardo Barbosa Lucena ${ }^{3}$
}

\begin{abstract}
Knupp S.N.R., Borburema C.C., Oliveira Neto T.S., Medeiros R., Knupp L.S., Riet-Correa F. \& Lucena R.B. 2014. [Outbreaks of primary photosensitization in equidae caused by Froelichia humboldtiana.] Surtos de fotossensibilização primária em equídeos causados por Froelichia humboldtiana. Pesquisa Veterinária Brasileira 34(12):1191-1195. Programa de Pós-Graduação em Medicina Veterinária, Universidade Federal de Campina Grande, Centro de Saúde e Tecnologia Rural, Campus de Patos, Av. Universitária s/n, Bairro Santa Cecília, Cx. Postal 61, Patos, PB 58708-110, Brazil. E-mail: sheilanribeiro@hotmail.com

The study was conducted in order to report outbreaks of photosensitization caused by Froelichia humboldtiana in equidae in the state of Rio Grande do Norte, Brazil. Animals from three farms and donkeys found abandoned in roads were examined. Peripheral blood samples were collected from five donkeys and two horses for analysis of serum activities of liver enzymes and concentrations of total, direct and indirect bilirubin. Skin biopsies were collected from two donkeys and a horse for histopatological exams. Fifty donkeys, 18 horses and two mules were affected. Of the affected donkeys, 45 were raised on roadsides and 30 died due to myiasis and weakness. The animals had a history of presenting skin lesions of photodermatitis about one month after being grazing in areas invaded by F. humboldtia$n a$ and recovered 10-30 days after being removed from these areas. If the animals were reintroduced in the paddocks with $F$. humboldtiana, pruritus and self-mutilation returned in a week or two. Young and adults donkeys showed extensive ulcerated wounds, that drained abundant serous exudate. All these wounds resulted from trauma caused by secondary self-mutilation to intense itching. In addition, many wounds had myiasis. The horses and mules had lesions of photodermatitis only in the areas of depigmented skin, no ocular lesions were observed. Histopathology of skin biopsies revealed perivascular inflammation in the superficial dermis. The epidermis had extensive ulcers, covered by fibrin associated with neutrophilic infiltrate and numerous basophilic bacterial aggregates. The serum activities of AST, GGT and serum concentrations of bilirubin were within normal ranges. The diagnosis of primary photosensitization associated with ingestion of $F$. humboldtiana was based on the epidemiology, clinical signs, serum biochemistry, skin lesions, and the recurrence of lesions after the reintroduction of the animals into the pasture invaded by the plant. F. humboldtiana is an important cause of primary photosensitization in equidae in the Brazilian semiarid region, resulting in weakness and death of large numbers of animals, mainly donkeys that don't receive proper treatment.
\end{abstract}

\footnotetext{
${ }^{1}$ Recebido em 6 de novembro de 2014.

Aceito para publicação em 21 de novembro de 2014.

${ }^{2}$ Programa de Pós-Graduação em Medicina Veterinária, Universidade Federal de Campina Grande (UFCG), Centro de Saúde e Tecnologia Rural (CSTR), Av. Universitária s/n, Bairro Santa Cecília, Patos, PB 58708-110, Brasil. *Autor para correspondência: sheilanribeiro@hotmail.com

${ }^{3}$ Departamento de Ciências Veterinárias, Laboratório de Patologia Veterinária, Universidade Federal da Paraíba (UFPB), Centro de Ciências Agrá-
}

rias (CCA), Campus II, Cidade Universitária, Areia, PB 58397-000, Brasil. E-mails: caioborburema@hotmail.com, temivet@hotmail.com, lucena.rb@ gmail.com

${ }^{4}$ Unidade Acadêmica de Medicina Veterinária, CSTR-UFCG, Patos, PB. E-mails: rmtmed@uol.com.br, franklin.riet@pq.cnpq.br

${ }^{5}$ Programa de Pós-Graduação Integrado em Zootecnia, CCA-UFPB, Campus II, Cidade Universitária, Areia, PB 58397-000. E-mail: leonardoknupp@ hotmail.com 
INDEX TERMS: Poisonous plants, primary photosenzitization, equidae, ervanço, Froelichia humboldtiana, photodermatitis, plant poisoning.

RESUMO. 0 presente trabalho foi conduzido com o objetivo de relatar surtos de fotossensibilização causados por Froelichia humboldtiana em equídeos no Estado do Rio Grande do Norte, Brasil. Foram examinados animais de três propriedades rurais, além de asininos abandonados nas estradas. Procedeu-se a coleta de amostras de sangue periférico de cinco jumentos e dois equinos para análise das atividades das enzimas hepáticas e concentrações de bilirrubina total, direta e indireta. Das áreas de pele com lesões de dois jumentos e de um equino foram realizadas biópsias. Constatou-se que 50 asininos, 18 equinos e duas mulas foram acometidos. Dos asininos acometidos, 45 eram jumentos criados soltos em margens de estradas. Relatou-se a morte de 30 jumentos em decorrência de miíases e debilidade. Os animais tinham histórico de apresentarem lesões de fotodermatite aproximadamente um mês após pastarem em áreas invadidas por F. humboldtiana e recuperavam-se das lesões 10 a 30 dias após serem retirados dessas áreas. Porém, o quadro de prurido e automutilação retornava em uma ou duas semanas quando os equídeos eram reintroduzidos nessas áreas. Ao exame clínico de asininos jovens e adultos, foram observadas feridas extensas, ulceradas, que drenavam exsudato seroso abundante. Todas essas feridas decorriam de traumas causados por automutilação secundária ao intenso prurido. Além disso, muitas das feridas apresentavam mí́ase. Os equinos e as mulas apresentavam lesões de fotodermatite somente nas áreas de pele despigmentadas, não sendo observadas lesões oculares. A avaliação histopatológica de biópsias de pele revelou inflamação perivascular na derme superficial. Na epiderme havia extensas úlceras, recobertas por fibrina associada a infiltrado neutrofílico e numerosos agregados bacterianos basofílicos superficiais. As atividades séricas de AST, GGT e as concentrações de bilirrubina no soro estavam dentro dos valores de referência. 0 diagnóstico de fotossensibilização primária associada à ingestão de $F$. humboldtiana foi baseado na epidemiologia, sinais clínicos, bioquímica sérica, biópsia de pele e reocorrência das lesões após os animais serem reintroduzidos no pasto invadido pela planta. Conclui-se que $a$ F. humboldtiana é uma importante causa de fotossensibilização primária em equídeos no semiárido brasileiro, resultando em quadro de debilidade e morte de grande número de animais, principalmente asininos que não recebem tratamento adequado.

TERMOS DE INDEXAÇÃO: Plantas tóxicas, fotossensibilização primária, equídeos, ervanço, Froelichia humboldtiana, fotodermatite, intoxicação por plantas.

\section{INTRODUÇÃO}

Em equinos a fotossensibilização é observada no semiárido do Nordeste do Brasil há vários anos (Pimentel et al. 2007). No entanto, muitas vezes os criadores erroneamente a definem como "sarna", não realizando o tratamento adequado o que, consequentemente, aumenta os custos com a criação, os quais podem se tornar ainda maiores quando resulta em morte dos animais.
Estudos de surtos naturais e reprodução experimental comprovaram que a planta Froelichia humboldtiana (Amaranthacea), popularmente conhecida como ervanço, é uma importante causa de fotossensibilização em ovinos (Pimentel et al. 2007) e bovinos (Souza et al. 2012) no semiárido do Brasil. Há descrição experimental de fotossensibilização na pele despigmentada de um equino colocado para pastar por 25 dias em área infestada por $F$. humboldtiana, com regressão das lesões 15 dias após o animal ser retirado dessa área (Pimentel et al. 2007). Em outro experimento, dois equinos que permaneceram em uma área onde ingeriam exclusivamente $F$. humboldtiana, apresentaram fotodermatite quatro dias após o início da ingestão (Medeiros et al. 2014). Entretanto, não existem relatos de surtos naturais de fotossensibilização em equídeos causados pela ingestão do ervanço. Este estudo descreve casos naturais de fotossensibilização primária associada à ingestão de $F$. humboldtiana em asininos, equinos e muares no Nordeste do Brasil.

\section{MATERIAL E MÉTODOS}

Os dados epidemiológicos e as avaliações clínicas foram obtidos a partir de visitas a três propriedades com equídeos acometidos por fotossensibilização no município de Assú, estado do Rio Grande Norte, Brasil. 0 município de Assú $\left(05^{\circ} 34^{\prime} 37,2^{\prime \prime}\right.$ de latitude Sul e 3654'32,4" de longitude Oeste) está localizado em região semiárida de clima seco e muito quente, com apenas duas estações bem definidas, estação chuvosa de março a abril, e seca no restante do ano, com média pluviométrica de 750,8mm (IDEMA 2008).

O histórico clínico dos animais foi obtido em entrevistas com os proprietários e médicos veterinários que atenderam os animais anteriormente. Foram examinados asininos, equinos e muares distribuídos em três propriedades. A propriedade A possuía 24 equinos, duas mulas e dois jumentos; a propriedade B possuía três jumentos; e a propriedade $\mathrm{C}, 45$ jumentos, porém, a maioria desses asininos não apresentava doma, nem manejo adequado, pois eram recolhidos das margens de estradas pelos moradores de um assentamento rural e transferidos para uma área com aproximadamente 200 hectares altamente invadida por Froelichia humboldtiana. Os animais das propriedades A e B, após os surtos de fotossensibilização, foram retirados do pasto invadido por $F$. humboldtiana e colocados em local sombreado com alimentação à base de farelo de milho e capim elefante (Pennisetum purpureum) por até 30 dias. Durante este período, os animais receberam tratamento tópico com antibiótico e repelente. Quanto aos jumentos da propriedade $\mathrm{C}$, o tratamento era esporádico e em apenas alguns animais, devido à dificuldade de captura dos mesmos.

A coleta de amostras de sangue periférico foi realizada em cinco jumentos e dois equinos para análise no soro das atividades das enzimas gama-glutamiltransferase (GGT) e aspartato-aminotransferase (AST) e as concentrações de bilirrubina total, direta e indireta. Também foram colhidas biópsias de pele com lesões de dois jumentos e um equino, um animal de cada propriedade incluída no estudo, selecionados de forma aleatória. As amostras colhidas foram fixadas em formol tamponado $10 \%$ e posteriormente processadas rotineiramente e coradas com hematoxilina e eosina (H\&E), ácido periódico de Schiff (PAS) e pela coloração de prata metenaminade Grocott. 


\section{RESULTADOS}

Os casos de fotodermatite ocorreram entre os meses de março a maio, época do período de chuvas no município de Assú, no ano de 2014. As três propriedades visitadas que possuíam animais com suspeita de fotossensibilização apresentavam as pastagens invadidas por Froelichia humboldtiana em intensa floração (Fig.1). Ao longo das estradas, onde foram encontrados asininos acometidos por fotossensibilização, havia também grande quantidade de $F$. humboldtiana (Fig.2), que é uma planta palatável para os equídeos, conforme observado durante visitas técnicas.

De acordo com informações fornecidas pelos proprietários e com as avaliações clínicas, um total de 50 asininos, 18 equinos e duas mulas foram acometidos por fotossensibilização. Apenas seis equinos da propriedade A não apresentaram lesões de fotossensibilização por não possuírem áreas despigmentadas de pele. Destaca-se, ainda, o relato, por parte dos criadores, da morte de 30 jumentos da propriedade $\mathrm{C}$, em sua maioria animais jovens, em decorrência

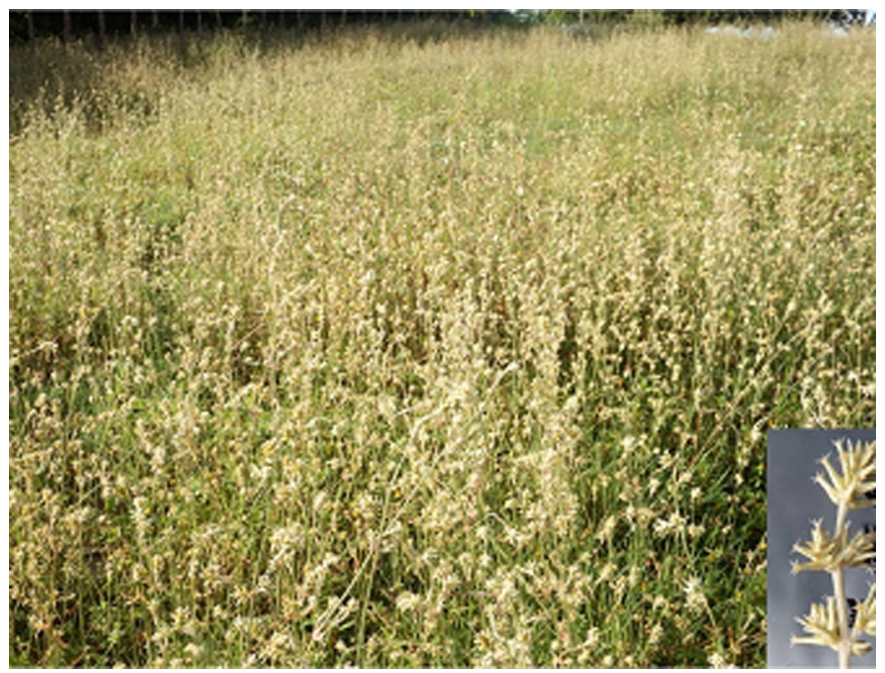

Fig.1. Pastagem invadida por grande quantidade de Froelichia humboldtiana. Notar a inflorescência da planta.

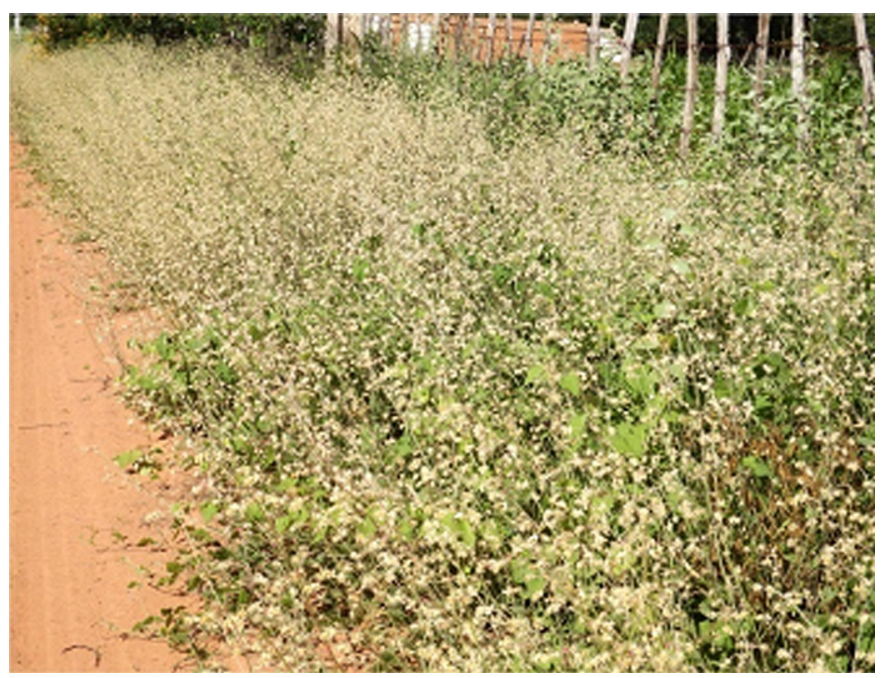

Fig.2. Grande quantidade de Froelichia humboldtiana na margem da estrada.

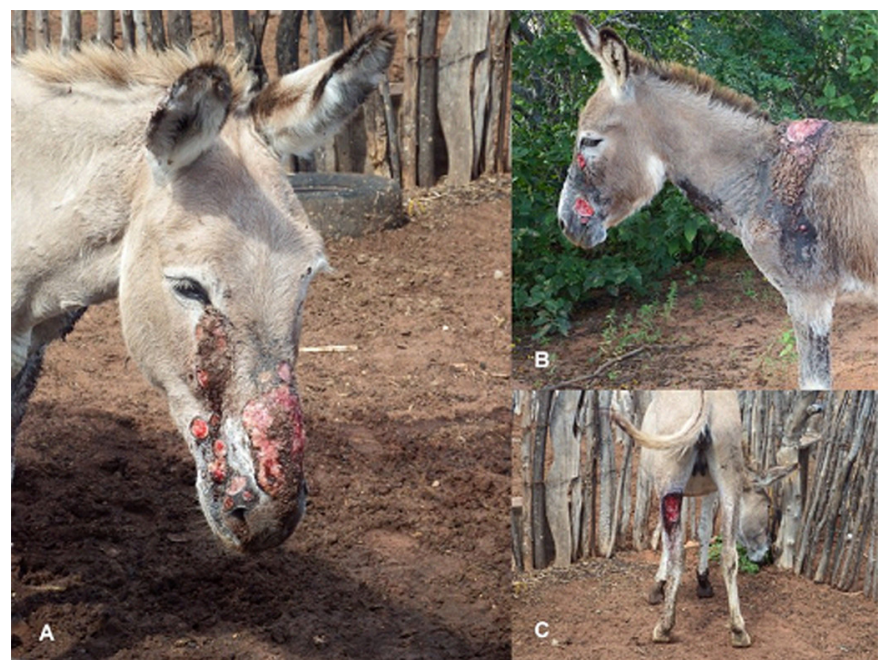

Fig.3. Animais acometidos por fotossensibilização associada à ingestão de Froelichia humboldtiana. (A) Jumenta apresentando múltiplas úlceras e áreas alopécicas. (B) Asinino com feridas extensas e ulceradas na face e cernelha.(C) Extensa ferida ulcerada no posterior da coxa de uma jumenta.

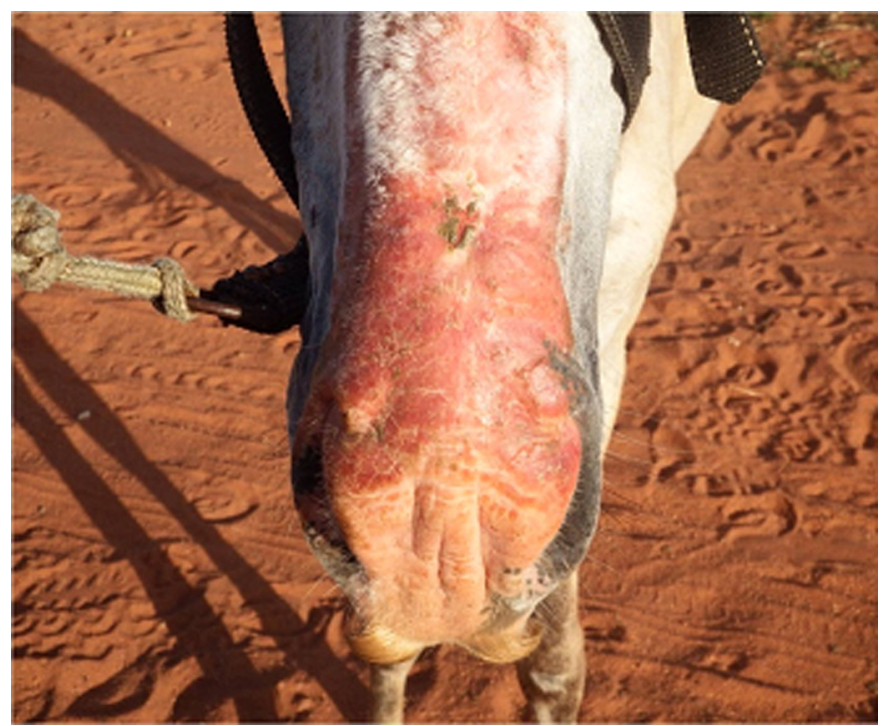

Fig.4. Cavalo com extensa lesão caracterizada por alopecia, hiperemia e crostas na área de pele despigmentada associada à ingestão de Froelichia humboldtiana.

de debilidade e miíases secundárias às lesões ocasionadas pela fotossensibilização.

Os asininos criados nas propriedades A e B tinham histórico de apresentarem lesões de fotodermatite aproximadamente 30 dias após pastarem em áreas invadidas por $F$. humboldtiana e recuperavam-se das lesões 20 a 30 dias após serem retirados dessas áreas e receberem tratamento com repelente e antibiótico tópico. Porém, o quadro de prurido e automutilação retornava em uma ou duas semanas quando os jumentos eram reintroduzidos nessas áreas. Já os equinos e as mulas, foram acometidos após pastarem por 10 a 20 dias nas áreas invadidas pela planta. Após serem retirados dos locais invadidos pela planta, os animais recuperavam-se das lesões após 15 a 20 dias. No entanto, as lesões retornaram aproximadamente 10 dias após estes 
serem reintroduzidos nessas áreas e só regrediam quando eram novamente removidos do pasto invadido pela planta.

Ao exame clínico de asininos jovens e adultos foi observado que todos estavam magros (propriedades A e B)ou caquéticos (propriedade C) e apresentavam feridas extensas, ulceradas, que drenavam exsudato seroso abundante. As feridas eram restritas à face, cernelha, região lombar, flanco e região posterior da coxa, inclusive em áreas pigmentadas da pele que estavam, também, alopécicas (Fig.3). Todas essas feridas decorriam de traumas causados por automutilação secundária ao intenso prurido que os jumentos demonstravam e muitas feridas apresentavam miíases.

Os equinos e mulas estavam com boa condição corporal e apresentavam lesões de fotodermatite somente nas áreas de pele despigmentadas. As lesões eram mais superficiais que as observadas em asininos e caracterizavam-se por hiperemia, alopecia e presença de crostas (Fig.4). Nenhum dos animais que apresentaram fotodermatite descrita neste estudo possuía lesões oculares.

A avaliação histopatológica de biópsias de pele revelou inflamação na derme superficial, circundando vasos sanguíneos, constituída por mastócitos, linfócitos, plasmócitos, alguns linfócitos e raros eosinófilos. Na epiderme havia extensas úlceras, recobertas por fibrina associada a infiltrado neutrofílico e numerosos agregados bacterianos basofílicos superficiais. Na avaliação com PAS e prata metenamina de Grocott, não foram observadas hifas fúngicas. As atividades séricas de AST, GGT e as concentrações de bilirrubina no soro estavam dentro dos valores de referência normais para a espécie equina.

\section{DISCUSSÃO}

Froenlichia humboldtiana é uma planta amplamente distribuída na região nordeste do Brasil e também encontrada em algumas áreas do Centro-Oeste (Marchioretto et al. 2002). Como observado nos surtos relatados neste artigo e por relatos de alguns criadores, essa planta é altamente palatável e, mesmo quando em menor quantidade, os animais tendem a selecioná-la em sua alimentação, principalmente os equídeos (Macedo et al. 2006, Pimentel et al. 2007, Medeiros et al. 2014). A grande disponibilidade da planta, principalmente nos meses chuvosos, associada à alta palatabilidade, resultou nos surtos de fotossensibilização, com morte de asininos, os quais não eram devidamente tratados e nem retirados das áreas invadidas pela planta.

Os asininos, anteriormente bastante utilizados como meio de transporte e animais de carga no Nordeste brasileiro, apresentam atualmente menor valor comercial, vivendo abandonados e vagando em logradouros e rodovias até serem recolhidos pelas prefeituras ou moradores locais, tornando-se mais fragilizados e com a alimentação ainda mais comprometida (Salles 2013). Essa realidade favoreceu a ocorrência dos óbitos observados em asininos que viviam abandonados em rodovias com margens infestadas por F. humboldtiana, por proporcionar o desenvolvimento de graves lesões cutâneas, e facilitar a ocorrência de miíase e contaminação secundária. Nos asininos, as lesões foram registradas não somente em áreas despigmentadas, mas em regiões do corpo sujeitas a traumas, como mordi- das e escoriações em troncos de árvores e cercas. As lesões auto-traumáticas decorriam do intenso prurido associado à fotodermatite. Lesões semelhantes foram descritas em bovinos, principalmente decorrentes de lambeduras associadas ao prurido ocasionado pela fotossensibilização, inclusive em áreas pigmentadas da pele (Souza et al. 2012). Nos equinos e muares, as lesões estavam restritas às áreas despigmentadas da pele e não correram lesões de automutilações como às observadas nos asininos e descritas anteriormente em bovinos.

Existem diversas doenças que causam lesões cutâneas semelhantes às decorrentes da fotossensibilização em asininos deste estudo, sendo recomendável realizar biópsia de lesões granulomatosas e ulcerativas na pele de equídeos para possibilitar o diagnóstico correto (Sallis et al. 2003). Dentre essas doenças pode-se citar a pitiose, o carcinoma de células escamosas e a habronemose. No estágio mais avançado dessas doenças pode-se observar ulceração da pele ou tecido de granulação proeminente ou, ainda, exsudação de líquido serossanguinolento. Porém, nos casos de pitiose podem-se observar os "kunkers" (massas necróticas de coloração amarelada) na avaliação macroscópica e hifas fúngicas na histopatologia (Pereira \& Meireles 2007). Nos casos de carcinoma de células escamosas, a observação de queratinócitos neoplásicos ao exame histopatológico permite sua diferenciação com outras lesões cutâneas (Fernandes 2007). Quanto à habronemose equina, microscopicamente apresenta-se distinta por formar rastros de migração larval preenchidos com debris e circundados por tecido fibrovascular rico em eosinófilos (McGavin \& Zachary 2009). Além dessas diferenças morfológicas, as lesões de fotossensibilização pela ingestão de $F$. humbolditiana diferenciam-se de outras doenças por regredirem quando os animais são colocados na sombra e impedidos de ingerir a planta.

É importante ainda se ter o conhecimento dos tipos de fotossensibilização, para se efetuar um diagnóstico preciso. São descritos três tipos de fotossensibilização: fotossensibilização primária (Tipo 1); fotossensibilização congênita (Tipo 2, há síntese de pigmentos aberrantes); e fotossensibilização hepatógena, ou secundária (Tipo 3) (Radostits et al. 2007). 0 Tipo 1, corresponde à manifestação primária e surge devido à ingestão de substâncias exógenas com ação fotodinâmica (Haargis \& Ginn 2007, Radostits et al. 2007). A fotossensibilização congênita (Tipo 2) é rara em animais domésticos, estando associada com o metabolismo anormal de porfirinas, resultando no acúmulo de substâncias fotodinâmicas no interior dos tecidos. Já a fotossensibilização Tipo 3, ou secundária, ocorre quando a capacidade do fígado para excretar a filoeritrina, pigmento derivado da degradação da clorofila no trato digestivo, é prejudicada (Haargis \& Ginn 2007). Nos casos espontâneos relatados, as atividades séricas de GGT e AST e as concentrações séricas de bilirrubina mantiveram-se dentro dos valores de referência para a espécie equina (Kaneko 1989, Meyer et al. 1992), demonstrando que a fotossensibilização é primária, assim como outros estudos já haviam relatado (Pimentel et al. 2007, Souza et al. 2012, Medeiros et al. 2014). Este diagnóstico foi baseado na epidemiologia, sinais clínicos, bioquímica sérica e biópsia de pele, que excluem lesões de outras etiologias e, 
por fim, pela recorrência das lesões após os animais serem reintroduzidos no pasto invadido pela planta. Além disso, a regressão das lesões de pele após os animais serem retirados das áreas infestadas por F. humboldtiana e o reaparecimento dessas lesões aproximadamente 10 dias após serem reintroduzidos nessas pastagens confirmam a relação entre a ingestão da planta e a fotodermatite.

As plantas que causam fotossensibilização primária incluem as que contêm naftodiantronas como componentes fotodinâmicos, dentre elas estão Fagopyrum esculentum e Hypericum perforatum, que apresentam, respectivamente, a fagopirina (Cheeke 1998) e a hipericina (Araya \& Ford 1981). Inclui-se, também, as que contêm furocumarinas, como Ammi majus (Méndez et al. 1991), Thamnosma texana (Oertli et al. 1983), Cymopterus watsonii (Stermitz \& Thomas 1975) e Cooperia pedunculata (Casteel et al. 1988, Rowe \& Norman 1989), sendo que, dentre estas, A. majus é a única planta relatada anteriormente no Brasil como causa de fotossensibilização primária em bovinos (Méndez et al. 1991). A toxina responsável pela fotodermatite causada por $F$. humboldtiana é desconhecida. Porém, com base na ausência de lesões oculares em animais afetados, sugere-se que esta planta contenha naftodiantronas ou substâncias similares (Pimentel et al. 2007). No entanto, o composto 3,4-di-hidroxifenil polifenólicacafeato foi identificado em Froelichia floridana (Wang et al. 2009) e esta substância também é encontrada na A. majus (Hehmann et al. 2004), sugerindo um novo composto potencialmente fototóxico.

\section{CONCLUSÃO}

Froelichia humboldtiana é uma importante causa de fotossensibilização primária em equídeos no semiárido brasileiro, podendo resultar no surgimento de mí́ases, quadro de debilidade e morte de asininos acometidos. Estudos futuros deverão ser conduzidos no intuito de determinar a toxina presente em $F$. humboldtiana responsável pelo quadro de fotodermatite, assim como para avaliar se há diferença de resistência entre as espécies de equídeos. Como método de profilaxia, é necessário evitar a introdução de equídeos e mulas que apresentem áreas de pele despigmentadas em locais invadidos pela planta.

Agradecimentos.- Este trabalho foi realizado com apoio da CAPES (Coordenação de Aperfeiçoamento de Pessoal de Nível Superior, Brasil) por meio de bolsa do Programa Pós-Graduação em Medicina Veterinária, e financiado pelo Instituto Nacional de Ciência e Tecnologia (INCT) para o estudo do Controle das Intoxicações por Plantas (CNPq Proc. 573534/2008-0).

\section{REFERÊNCIAS}

Araya O.S. \& Ford E.J.H. 1981. An investigation of the type of photosensitization caused by the ingestion of St John's wort (Hypericum perforatum) by calves. J. Comp. Pathol. 91:135-141.

Casteel S.W., Rowe L.D. \& Bailey E.M. 1988.Experimentally induced photosensitization in cattle with Cooperia pedunculata. Vet. Hum. Toxicol. 30:101-104
Cheeke P.R. 1998. Natural Toxicants in Feeds, Forages, and Poisonous Plants. $2^{\text {nd }}$ ed. Interstate, Danville, Illinois. $479 \mathrm{p}$.

Fernandes C.G. 2007. Neoplasias em ruminantes e eqüinos, p.650-656. In: Riet-Correa F., Schild A.L., Lemos R.A.A. \& Borges J.R.J. (Eds), Doenças de Ruminantes e Equídeos. $3^{\text {a }}$ ed. Palloti, Santa Maria, RS.

Haargis A.M. \& Ginn P.E. 2007.The integument, p.1107-1261. In: McGavin M.M. \& Zachary J.F. (Eds), Pathologic Basis of Veterinary Disease. $4^{\text {th }}$ ed. Mosby/Elsevier, St Louis.

Hehmann M., Lukac R., Ekiert H. \& Matern U. 2004. Furanocoumarin biosynthesis in Ammi majus L. cloning of bergaptol O-methyltransferase. Eur. J. Biochem. 271:932-940.

IDEMA 2008. Instituto do Desenvolvimento Econômico e Meio Ambiente do Rio Grande do Norte. Disponível em <http://adcon.rn.gov.br/ACERVO/idema/DOC/DOC000000000016656.PDF> Acesso em 10 out. 2014.

Kaneko J.J. 1989. Clinical Biochemistry of Domestic Animals. $4^{\text {th }}$ ed. Academic Press, London.

Macedo M.C., Bezerra M.B. \& Soto-Blanco B. 2006. Fotossensibilização em animais de produção na região semi-árida do Rio Grande do Norte. Arqs Inst. Biológico, São Paulo, 73(2):251-254.

Marchioretto M.S. \& Windisch P.G. \& Siqueira J.C. 2002. Os gêneros Froelichia moench e Froelichiella R.E. Fries (Amaranthaceae) no Brasil. Pesq. Bot. 52:7-46.

McGavin M.D. \& Zachary J.F. 2009. Bases da Patologia em Veterinária. 4aํed. Elsevier, Rio de Janeiro. 1475p.

Medeiros R.M.T., Bezerra V.K.D. \& Riet-Correa F. 2014. Intoxicação experimental por Froelichia humboldtiana em equinos. Ciência Rural. (Online)

Meyer D.J., Coles E.H. \& Rich L.J. 1992. Veterinary Laboratory Medicine. W.B. Saunders, Philadelphia.

Méndez M.C., Riet-Correa F., Schild A.L., Ferreira J.L. \& Pimentel M.A. 1991. Fotossensibilização em bovinos causada por Ammi majus (Umbelliferae) no Rio Grande do Sul. Pesq. Vet. Bras. 11(1/2):17-19.

Oertli E.H., Rowe L.D. \& Lovering S.L. 1983. Phototoxic effect of Thamnosa texana (Dutchman's breeches) in sheep. Am. J. Vet. Res. 44:1126-1129.

Pereira D.B. \& Meireles M.A. 2007. Pitiose, p.457-466. In: Riet-Correa F., Schild A.L., Lemos R.A.A. \& Borges J.R.J. (Eds), Doenças de Ruminantes e Equídeos. Vol.1. 3aㅡ ed. Pallotti, Santa Maria, RS. 719p.

Pimentel L.A., Riet-Correa F., Guedes K.M., Macêdo J.T.S.A., Medeiros R.M.T. \& Dantas A.F.M. 2007. Fotossensibilização primária em equídeos e ruminantes no semi-árido causada por Froelichia humboldtiana (Amaranthaceae). Pesq. Vet. Bras. 27(1):23-28.

Radostits O.M., Gay C.C., Hinchcliff K.W. \& Constable P.E. 2007. Veterinary Medicine: a textbook of the diseases of cattle, horses, sheep, pigs and goats. $10^{\text {th }}$ ed. W.B. Saunders, London. 2065p.

Rowe L.D. \& Norman J.O. 1989. Detection of phototoxic activity in plant specimens associated with primary photosensitization in livestock using a simple microbiological test. J. Vet. Diagn. Invest. 1:269-270.

Salles P.A., Sousa L.O., Gomes L.P.B., Barbosa V.V., Medeiros G.R., Sousa C.M. \& Weller M. 2013. Analysis of the population of equidae in semiarid region of Paraíba. J. Biotech. Biodiv. 4(3):269-275.

Sallis E.S.V., Pereira D.I.B. \& Raffi M.B. 2003. Pitiose cutânea em equinos: 14 casos. Ciência Rural 33(5):899-903.

Souza P.E.C., Oliveira S.S., Aguiar-Filho C.R., Cunha A.L.B., Albuquerque R.F., Evêncio-Neto J., Riet-Correa F. \& Mendonça F.S. 2012. Primary photosensitization in cattle caused by Froelichia humboldtiana. Res. Vet. Sci. 93:1337-1340.

Stegelmeier B.L. 2002. Equine photosensitization. Clin. Tech. Eq. Pract. 2:81-88.

Stermitz F.R. \& Thomas R.D. 1975. Furocoumarins of Cymopterus watsonii. Phytoc. 14:168.

Wang P., Li S., Ownby S., Zhang Z., Yuan W., Zhang W. \& Beasley R.S. 2009. Ecdysteroids and a sucrose phenylpropanoid ester from Froelichia floridana. Phytoc. 70:430-436. 